\title{
Dinâmicas e constrangimentos nos processos de organização dos trabalhadores informais na Guiné-Bissau
}

\author{
Magdalena Bialoborska
}

\begin{abstract}
Resumo
Os processos de organização entre os trabalhadores informais na Guiné-Bissau são, normalmente, pautados por uma dinâmica multiplicada por diversos organismos, como associações, sindicatos, cooperativas. As organizações, tanto formalizadas, como informais, existem em vários sectores da actividade económica e envolvem uma parte significativa dos trabalhadores.

A inexistência de dados exactos sobre a dimensão da economia informal na Guiné, não permite estimar a proporção entre os trabalhadores informais organizados e os que não pertencem às associações. 0 artigo apresenta uma análise mais profunda de funcionamento de algumas das organizações - através de resultados de pesquisa de terreno, que incluiu, além de entrevistas com os membros e corpos directivos, também a observação directa, as conversas informais - e identifica os constrangimentos que limitam o desempenho de actividades programadas pelas associações, e, em consequência, os benefícios que estas podem fornecer aos seus membros.
\end{abstract}

\section{Palavras-chave}

Economia informal, organizações na economia informal, comércio informal, transporte informal.

\section{Introdução}

0 desenvolvimento e a crescente importância do sector informal na Guiné-Bissau foram notificados nos anos 90 e têm sido considerados como as consequências directas dos Programas de Ajustamento Estrutural (PAE), introduzidas no país em 1987 [Duarte et al. 1996: 97]. No decorrer das últimas quase três décadas que distanciam a introdução dos PAE dos dias de hoje, a dimensão da economia informal não diminuiu, supõe-se - não existem dados exactos - que esta fornece 
rendimentos a cada vez maior número de pessoas, garantindo desta forma os meios de sobrevivência a uma grande parte da população guineense. A dupla face de informalidade ${ }^{1}$, destacada pelo Director Geral da Organização Internacional de Trabalho (OIT) numa fase ainda bastante inicial do debate acerca do fenómeno ${ }^{2}$ [0IT 1991], foi sempre um entrave para a concepção de soluções que possam satisfazer vários grupos envolvidos. Por enquanto, por falta de alternativas, a existência da economia informal parece ser tolerada pelos Estados, mesmo que o valor de capitais que circulam neste sector, paralelo a o formal, seja bastante elevado. 0 foco de atenção, desde o limiar de séculos, dirigiu-se para o trabalho decente, cujo défice é cada vez maior, e o debate em torno de direitos de trabalhadores, também os que permanecem na informalidade, tomou o lugar principal no discurso da OIT [0IT 1999a, 2002, 2007a, 2007b].

No caso da Guiné-Bissau, nota-se um interesse bastante reduzido, por parte do Estado, em relação às questões relacionadas com a economia informal. Nunca foi procedida a tentativa de medir a sua dimensão, não foram postas em debate as propostas de formalização do informal, não houve debate sobre a precariedade das condições de trabalho da maioria das pessoas pertencentes a este sector, e, finalmente, nunca foram tomadas iniciativas no sentido de organizar os trabalhadores informais. Este último caminho foi considerado, tanto pela OIT, como por governos de vários países, por um lado, como uma das formas de ganhar mais eficácia por parte dos próprios trabalhadores informais na resolução dos problemas com os quais têm que lidar, e, por outro lado, para facilitar a comunicação entre governo e representantes do sector que, organizados e unidos, têm mais capacidade de dialogar sobre as suas necessidades.

Entretanto, a falta de incentivos "de cima" não teve influência nos processos de organização dos trabalhadores informais guineenses tendo, já nos anos 90, muito antes das oficiais recomendações da OIT [1999a, 1999b, 2002, 2007b, 2009], surgido as primeiras organizações na economia informal, bem como recomendações para a sua criação por parte do meio académico ou não-governamental [Duarte et.al. 1996]. As dinâmicas organizacionais no sector informal na Guiné-Bissau superam bastante as dinâmicas neste sentido noutros PALOP. 0 número de organizações dos trabalhadores informais, tanto as registadas como as que funcionam de forma irregular, é bastante elevado. Até agora não foi feito nenhum estudo ou inquérito que fornecesse os dados exactos acerca destes processos, no entanto repara-se a existência de grupos organizados dos trabalhadores nos mais diversos sectores da economia informal. Seria necessário um estudo aprofundado para compreender melhor a escala das dinâmicas associativas do sector informal.

0 presente artigo, baseado em grande parte na pesquisa de terreno que decorreu na Guiné-Bissau no ano 2013, tem como principal objectivo destacar algumas características próprias dos processos de organização na economia informal deste país.

1. Deve-se promover o sector como fornecedor de emprego ou tentar aplicar-Ihe as leis que funcionam no sector formal, o que pode causar a reducção do sector e paralelamente a diminuição das possíveis fontes de rendimento para um número significativo da população?

2. Mesmo que o complexo conceito de economia informal tenha surgido já no início dos anos 70 [Hart 1970; Hart 1973, 0IT 1972], 0 debate mais intenso sobre o fenómeno data aos anos 90. Neste debate o lugar de destaque foi sempre da OIT que dedicou bastante trabalho a investigação, reflexão, procura de pistas e soluções para questões relacionadas com informalidade. 
Como principais pontos de referência para uma análise comparativa, foram escolhidos resultados de outras pesquisas desenvolvidas por investigadores, que antecederam esta e que decorreram em dois países africanos: Cabo Verde e São Tomé e Príncipe, tendo-se seleccionado também literatura disponível sobre as organizações dos trabalhadores informais noutros países africanos [ex. Lindell 2010, Lopes 2010, Feliciano et al. 2008, Rogel 2006]. Em modo ilustrativo estão apresentadas algumas organizações dos trabalhadores informais guineenses, outras estão mencionadas para complementar a lista que, mesmo assim, permanece bastante incompleta. No entanto, este fragmento da complexa realidade informal guineense já permite perceber algumas das suas particularidades, entre as quais se destacam: i) o elevado número de organizações, ii) o envolvimento activo dos membros no funcionamento destas, especialmente na primeira fase do seu funcionamento iii) diversificação de áreas de actuação, iv) diversas limitações que prejudicam fortemente 0 seu funcionamento: internas e externas.

\section{Pesquisa e dados}

A inexistência de dados estatísticos sobre a economia informal na Guiné-Bissau, leva à necessidade de encontrar caminhos alternativos que permitam perceber a dimensão e a complexidade deste fenómeno. A situação socioeconómica do país, apresentada mais adiante, tem como base os dados do Instituto Nacional de Estatística de Bissau, Banco Mundial (BM), Fundo Monetário Internacional (FMI), alguns indicadores recolhidos pelo African Economic Outlook e, por fim, os Indicadores de Desenvolvimento Humano do Programa das Nações Unidas para o Desenvolvimento (PNUD). A questão da informalidade está analisada de forma mais qualitativa do que quantitativa. Além de algumas fontes bibliográficas [Handem 2013; Camará 2010; Gomes 2008; Lourenço-Lindell 2002; Aguilar et.al. 2001; Monteiro 1996], o material analisado provém da pesquisa de terreno que decorreu na Guiné-Bissau, em Novembro de 2013, e serve unicamente para uma análise qualitativa. A curta duração da pesquisa foi o obstáculo para uma recolha mais profícua, mas as propostas de desenvolvimento desta pesquisa foram elaboradas, esperando que possam, eventualmente, ser realizadas numa fase posterior ou por um outro projecto dedicado à informalidade da economia guineense.

Ao longo da pesquisa foram desenvolvidos, em paralelo, quatro tipos de recolha de dados: as entrevistas com os membros de associações dos trabalhadores informais, as entrevistas/conversas com os membros das organizações que têm capacidade de fornecer apoio às associações do sector informal, para proporcionar o seu melhor funcionamento, as conversas com os investigadores que estudam economia informal na Guiné e a observação directa, nos vários mercados e nos meios de transporte. Algumas informações e observações foram também procedidas durante o Atelier de capitalização, organizado pela Swiss Aid, que contou com a participação dos representantes de algumas das associações dos trabalhadores informais previamente entrevistadas.

3. Ver em: www.africaneconomicoutlook.org. 
No total foram entrevistadas 9 associações do sector informal: Associação dos Comerciantes do Mercado Central, Associação dos Retalhistas do Bairro Militar, Associação de Retalhistas dos Mercados da Guiné-Bissau (que ao mesmo tempo organiza o funcionamento do Mercado Bandim, o maior mercado do país), Associação Ajuda Mútua (Ghatenkar Ghaba na Ubon) da Granja de Pessubé, Associação Afrupeixe, Associação do Mercado Caracol, Associação dos Transportadores do Sector do Cacheu (ASTRASECA), Sindicato dos Motoristas da Administração Pública, Privada e Afins (SIMAPPA) e Associação Nacional de Produtores e Promotores de Arte (ANAPPA). Pode ainda acrescentar-se uma conversa, que aconteceu de forma espontânea no Porto Pindjiquity, com os operadores das pirogas, que servem como meio de transporte para as ilhas nas alturas em que os barcos ficam parados ${ }^{4}$, durante a qual se obteve a informação sobre as tentativas de criação de uma associação entre as pessoas envolvidas neste ramo do vasto sector de transportes. Entre os materiais recolhidos durante a pesquisa, foram seleccionadas oito associações que serão apresentadas mais adiante.

As entrevistas com representantes de duas organizações: Rede de Associações Juvenis (RAJ) $)^{5}$ ONG Força Guiné ${ }^{6}$ permitiram recolher informações acerca das iniciativas que estão a ser tomadas fora do sector informal e também observar a potencialidade destas no sentido de apoiar os trabaIhadores informais em várias etapas dos processos de organização.

Como a informalidade em Bissau se inclui em todos os sectores, e numa escala significativa, a observação foi desenvolvida praticamente durante toda a estadia no terreno. No entanto, importa destacar aqui a observação directa relacionada com o estudo de dois sectores: do comércio e dos transportes. A primeira decorreu em vários mercados da cidade de Bissau: Mercado Central, Mercado do Bairro Militar, Mercado Bandim, Mercado Caracol, Mercado Santa Luzia, mercado no Porto de Pesca, Mercado Artesanal de Bissau e no Mercado de Cabras e no Ponto de venda de Cibes (placas para construção), os dois últimos situados junto ao Instituto Nacional de Estudos e Pesquisa (INEP). Em relação ao sector dos transportes a observação foi desenvolvida tanto nas praças/paragens dos carros que transportam passageiros em Bissau e em Cacheu, como em movimento, durante numerosas deslocações de táxi $i^{7}$, toca-toca, ${ }^{8} 7$ plage ${ }^{9}$ e candonga ${ }^{10}$, na capital e entre as localidades (deslocação para Cacheu).

4. Por causa das avarias ou, como aconteceu desta vez, os pagamentos em atraso, levar os trabalhadores do barco, a negar de efectuar o serviço.

5. RAJ - Rede de Associações Juvenis, criada em 2004 e formalizada em 2005, a rede agrupa várias associações juvenis. Bastante dinâmica e bem organizada, ao longo dos últimos quase 10 anos do seu funcionamento conseguiu estabelecer várias parcerias com as organizaçoese internacionais e ONGse implementar diversos programas que pretendem melhorar as condiçōes de vida dos habitantes de Bissau, especialmente focados nas camadas mais jovens. Desenvolvem também diversas actividades culturais. (entrevista com os membros da RAJ, Bissau, 14/11/13)

6. A Associação Força Guiné "tem como missão contribuir para a construção de uma cidadania activa e de uma sociedade democrática na Guiné, com a elevação do nível da reflexão e do debate sobre os assuntos importantes e conducentes ao desenvolvimento socioeconómico do país. (...) Para realizarmos a nossa missão, o grupo desenvolverá aç̧̄es tais como, a organização de conferências e workshops temáticos tanto em Bissau como nas regiōes, a promoção de debates e palestras nas universidddes e bairros, a promoç̧ão de sondagens e pesquisas sociais, a elaboração de propostas de projectos visionários para o país, entre outros." (através do site da associação: http://afguine.blogspot.pt/)

7. Os táxis na Guiné-Bissau são colectivos, e podem ser apanhados em qualquer lugar. Basta juntar-se às pessoas que já estão no táxi e seguem em direcção paralela ao nosso destino. Se for a primeira pessoa a apanhar o táxi, o motorista só levará as pessoas que seguem para os destinos íguais ao seu ou aos sítios que ficam a caminho. As taxas na cidade são de 150CFA e para as zonas mais distantes 200-300CFA.

8. Toca-toca é outra forma de transporte colectivo que leva as pessoas das zonas relativamente centrais do Bissau para os bairros. São os carros de uma 


\section{Guiné-Bissau: a instabilidade política e a situação socioeconómica}

A característica frequentemente indicada em relação a este pequeno país $(36544$ km²), situado na costa ocidental africana, é a sua instabilidade política e o papel que as Forças Armadas possuem na governação do país [Dias 2013].

A história da Guiné-Bissau como nação independente tem sido marcada pela instabilidade política, por desafios constantes à normalidade constitucional e pelo agravamento geral da insegurança, em especial desde o conflito de 1998-1999. Golpes de estado, contragolpes e intentonas, assassínios políticos na cúpula do poder e um padrão de desrespeito pelos direitos mais elementares dos indivíduos deixaram de ser a excepção e passaram a ser a regra. De 1998 a 2013, a Guiné-Bissau teve dez primeiros-ministros, eleitos sem terminar o mandato, quatro chefes de Estado-Maior, todos afastados por levantamentos militares (e dois foram assassinados em funções pelos militares) sem completar o mandato, e três Presidentes da República [Mendes 2013: 1-2].

0 ano em que decorreu a pesquisa de terreno que serve como o ponto de partida para este artigo, foi 0 ano de transição na Guiné-Bissau. Após o Golpe de Estado, que ocorreu em 12 Abril de 2012, e que teve graves consequências económicas e políticas, foi nomeado pelo Comando Militar o Presidente de Transição, Serifo Nhamadjo e, mais tarde, o Primeiro-ministro de Transição, Rui de Barros. A comunidade internacional (Comunidade Europeia, Nações Unidas, vários países) condenou o Golpe (DW 13/04/12), impondo diversas sanções, a União Africana suspendeu a Guiné-Bissau (DW 17/04/12) e várias instituições, entre elas o Banco Mundial e o Banco Africano de Desenvolvimento, anunciaram "a suspensão das suas ajudas ao desenvolvimento da Guiné-Bissau" (DW 19/04/12). Não só o apoio financeiro, mas também técnico foi suspenso. A situação sócio-económica do país, que ficou bastante isolado da cena internacional, piorou de forma significativa.

0 país, habitado em 2013 por 1,704,255 pessoas (dados do Banco Mundial1"), situa-se na cauda do Índice de Desenvolvimento Humano, ocupando 01770 lugar entre 187 países (UNDP 2014), com 0 valor de 0,396 pontos. A expectativa de vida à nascença é de 54,3 anos (UNDP 2014). 0 ratio de pobreza está estimado em 69,3\%, de acordo com os dados do Banco Mundial ${ }^{12}$ e os resultados de Inquérito Ligeiro para Avaliação da Pobreza [INE 2011]. Um terço da população (33\%) encontra-se em situação de pobreza extrema, vivendo com menos de 1,00\$ USD por dia [INE 2011]. Para meIhorar a situação da população do país, o governo costuma elaborar um plano estratégico nacional de redução da pobreza, cuja aplicação nem sempre é totalmente possível, devido à situação política [Ministério da Economia, do Plano e Integração Regional 2011: 11]. Actualmente, o segundo plano

dúzia de lugares, que normalmente levam o dobro de pessoas. Este tipo de transporte existe em todos os PALOPs, tendo a designação diferente em cada país: em Angola - candongueiros, Cabo Verde - hiaces, São Tomé e Príncipe - hiaces e Moçambique - chapas. Em Bissau o preço de viagem é de 100CFA.

9. São os carros que transportam os passageiros entre as localidades. 0 nome vem de número de lugares disponíveis: são 6 para os passageiros e um lugar de motorista.

10. Carros de mais de 10 lugares que garantem o transporte entre as localidades.

11. Ver em: http://data.worldbank.org/indicator/SP.POP.TOTL.

12. Ver em : http://data.worldbank.org/country/guinea-bissau. 
deste género (DENAPR II) preparado para o período 2011-2015, deveria estar já bastante avançado, entretanto 0 golpe de estado de 2012 influenciou de forma negativa o seu desenvolvimento e muito provavelmente vários dos objectivos estabelecidos não serão atingidos.

0 PIB do país, no valor de $\$ 858.7$ mil em 2013 (BM), provém em grande parte da agricultura e da pesca - 49,1\% do PIB em $2013^{13}$. No ano do último Golpe de Estado foi notado o decréscimo do PIB com o valor da taxa de crescimento estimado em - 1,5\%, mas o país conseguiu recuperar 0 crescimento positivo, mesmo que ainda bastante baixo, no valor de 0,3\%, em 2013. Para 0 ano 2014, o FMI prevê 0 crescimento de mais de 2 pontos percentuais ${ }^{14}$, o que significa que o país está gradualmente a recuperar das consequências do Golpe.

Em relação à actividade económica, de acordo com os dados mais recentes disponíveis (INE 2011), a taxa de actividade ${ }^{15}$ no país está estimada em $67,7 \%$. A percentagem da população activa ocupada oscila entre 44,6\% na cidade de Bissau e 73,2\% noutras regiões do país, o que dá uma média de 65,1\%. Há uma diferença significativa em relação ao género: a população masculina ocupada está estimada em 72,3\%, enquanto a população feminina ocupada se estima em 58,7\%. A taxa de desemprego é bastante baixa e oscila entre 1,2\% fora da cidade de Bissau e 13\% em Bissau, dando um valor médio de 3,7\% [INE 2011].

A Guiné-Bissau é um país essencialmente agrícola - este sector emprega 72,4\% da população activa [INE 2011]. Obviamente na cidade de Bissau esta percentagem é bastante distante da média do país e só ligeiramente ultrapassa os 10\% (11,6\%). Na cidade predominam empregos na área de serviços $(28,6 \%)$ e comércio (27,5\%). Em Bissau a taxa de desemprego é mais elevada e o sector informal mais desenvolvido. 0 défice de postos de emprego fornecidos pelo Estado ou por empresas privadas, faz com que os habitantes da cidade tenham de procurar meios que garantam a sua subsistência.

\section{Menos Estado, mais organização: sector informal na Guiné-Bissau}

0 rápido e intenso desenvolvimento do sector informal na Guiné-Bissau sucedeu a introdução dos Programas de Ajustamento Estrutural, sob égide do Fundo Monetário Internacional e do Banco Mundial na segunda metade dos anos 80 . Alguns dos efeitos destes programas, proporcionaram, directa ou indirectamente, várias mudanças em relação à economia informal, não apenas em termos quantitativos, mas também em termos estruturais.

Duarte e Gomes [1996], na sua análise do sector informal na Guiné dos anos 90, enumeram os impactos do PAE no sector, sublinhando dois aspectos de grande peso: i) aumento da taxa de desistência escolar causada por falta de condições para a continuação de estudo, tanto pela população masculina, como feminina, e também por causa da inadequação dos diplomas à situação no

13. Ver em: http://www.africaneconomicoutlook.org/en/countries/west-africa/guinea-bissau/

14. Ver em: http://www.ionline.pt/artigos/dinheiro/pib-da-guine-bissau-deve-crescer-27-este-ano-nove-vezes-mais-2013.

15. A taxa de actividade refere-se à percentagem da população com idade a partir dos 15 anos, disponível para trabalhar. 
mercado de trabalho formal, cuja capacidade de criação de novos postos de emprego foi bastante limitada; ii) despedimentos de assalariados, por um lado, e redução de salários, por outro lado. Estes dois aspectos levaram ao aumento de número de pessoas que foram forçadas a encontrar várias formas alternativas de conseguir receitas para sustentar as suas famílias.

Tudo isso levou ao aumento significativo do número de pessoas envolvidas em actividades informais transformando a estrutura deste sector, que contava com cada vez maior participação das mulheres, e baixando a taxa etária dos trabalhadores, empregando muitos jovens que desistiam de frequentar aulas, sabendo que isto não lhes ia garantir emprego no futuro. " 0 informal abrange a esmagadora maioria da população guineense, directa ou indirectamente e, dadas as características rurais do país, é muito reduzido o número daqueles que se encontram integrados no sistema formal" [Feliciano et.al. 2008: 61]. 0 sector abrange três categorias de actividades - actividades que garantem a sobrevivência, microempresas e pequenas e médias empresas - cada uma das quais possui as suas características próprias. As fronteiras desta classificação são bastante fluidas e muitas vezes há deslocações e sobreposições de actividades entre as categorias [Gomes 2008: 7]. Entretanto 0 esquema apresentado permite melhor entender a diversidade, complexidade e vasta dimensão da economia informal.

Na Guiné-Bissau, assim como noutras latitudes, o informal está directamente ligado a quatro aspectos, que prejudicam bastante a vida das pessoas pertencentes ao sector: i) rendimentos baixos e incertos, ii) condições precárias de trabalho, iii) défice de direitos, iv) falta de segurança social. Para conseguir superar alguns destes problemas, foi implementada a iniciativa - na sequência de acções tomadas tanto por próprios trabalhadores como resultado de impulsos vindos de fora - de organizar os trabalhadores informais. As directivas da OIT neste sentido surgiram nos finais dos anos 90 e no início do século XXI [OIT 1999a, OIT 1999b, OIT 2002, OIT 2007b, OIT 2009], mas no caso da Guiné-Bissau as iniciativas dos próprios trabalhadores informais foram anteriores a isso, mesmo as que foram tomadas depois parecem ter surgido, na maioria dos casos, por necessidade das pessoas envolvidas. Ao contrário das acções constatadas em Cabo Verde e São Tomé e Príncipe, onde nos deparamos com o envolvimento das centrais sindicais, do Estado e das organizações nãogovernamentais no processo de organização dos trabalhadores informais [Bialoborska 2013, Feliciano et.al. 2008], na Guiné-Bissau todas as iniciativas vêm no sentido bottom-up. Antes de juntar mais características que distinguem as organizações dos trabalhadores informais guineenses e de analisar brevemente os pontos fortes destes, assim como os constrangimentos que estas encontram no seu caminho, serão apresentadas algumas das associações para possibilitar a melhor percepção da análise apresentada mais adiante.

\section{Organizações dos trabalhadores informais na Guiné-Bissau: alguns exemplos}

A apresentação de algumas organizações dos trabalhadores informais que se segue tem como 
a base a pesquisa de terreno realizada na Guiné-Bissau e está ordenada de acordo com a área de actividade económica desenvolvida por seus membros. Das organizações cujos membros foram entrevistados ao longo da pesquisa, foram escolhidas oito associações e apresentadas aqui de forma mais detalhada, o que fornece al guns dados importantes para a análise dos processos de organização na economia informal na Guiné-Bissau.

\section{Comércio}

\section{Associação dos Comerciantes do Mercado Central (ASCOMC)}

0 Mercado Central de Bissau está localizado actualmente, e por um período indeterminado, nas instalações provisórias que foram disponibilizadas pela Câmara Municipal de Bissau depois do incêndio que no ano 2006 destruiu o espaço anterior, prejudicando gravemente os comerciantes.

A Associação dos Comerciantes do Mercado Central foi criada em 2003 e fazem parte dela todos os comerciantes que operavam no antigo mercado - mais de 450 pessoas. Após o incêndio, alguns dos vendedores, descontentes com a localização do espaço alternativo, escolheram outros mercados para aí tentar reconstruir o seu negócio e neste momento operam nas instalações temporárias do Mercado Central cerca de 260 comerciantes.

Entretanto, a associação continua a contar com o número inicial de sócios, mesmo que as suas acções estão limitadas ao nível local e focalizadas nas soluções de situações que prejudicam os vendedores no espaço actual. A associação foi constituída na sequência de várias situações que prejudicavam os comerciantes, entre elas as múltiplas tentativas de aumento da taxa cobrada pela Câmara por ocupação de espaço. Unidos, os vendedores conseguiram negociar com a Câmara.

A associação possui estatutos e corpo directivo, mas a dinâmica das suas actividades foi bastante enfraquecida, especialmente depois de mudança de instalações. Os sócios deixaram de pagar cotas, situação justificada com a falta de condições para o tal: 0 volume de negócios diminuiu de forma significativa - há dias em que não vendem literalmente nada e várias vezes são obrigados de deitar fora frutas ou legumes estragados ou levar para o seu próprio consumo, não obtendo, neste caso, nenhum lucro financeiro. Nunca receberam quaisquer apoios, mesmo quando houve promessas, por exemplo, por parte do banco onde a associação tem a conta, que se demostrou apto de a apoiar financeiramente, não chegando, no entanto, a disponibilizar quaisquer verbas. Os comerciantes acreditam que tudo vai mudar quando voltarem ao seu lugar inicial e as únicas acções desenvolvidas pela associação têm como objectivo pressionar a Câmara no sentido de esta recomeçar as obras do Mercado, cuja reconstrução foi interrompida pelo golpe de estado.

\section{Associação de Retalhistas dos Mercados da Guiné-Bissau (ARMGB)}

0 surgimento da Associação de Retalhistas dos Mercados da Guiné-Bissau nos anos 90 tem a ver com os abusos que os comerciantes sofriam: "de todo lado: Câmara Municipal, Finanças, Comércio, abusavam de nós. Pagávamos taxas, pagávamos alfândega e a Câmara mesmo assim abusava. 
Arranjamos um advogado, juntamo-nos e organizamos. Para conseguir negociar melhor tudo com 0 Estado" (entrevista colectiva, membros de ARMGB, Bissau, 12/11/13).

A iniciativa partiu dos próprios comerciantes, cujo número não foi elevado: inicialmente era 0 grupo de 10 pessoas, o que importa sublinhar, tendo em conta que actualmente esta é a maior associação guineense, chamada frequentemente de "associação-mãe", que ao longo do seu funcionamento se foi transformando numa rede de associações, que engloba várias organizações de trabalhadores na área de comércio retalhista, sendo que, actualmente, o número total dos associados que fazem parte da ARMGB está estimado em cerca de 80 mil pessoas.

Mesmo com este número elevado de membros, as suas actividades são bastante limitadas e a eficácia das suas acções fica muito aquém do que podia se esperar. Queixam-se de falta de apoios, sublinham a necessidade de tempo de antena na rádio nacional, indicam a incapacidade de contabilizar e controlar bem todas as organizações que englobam e, finalmente, indicam o incumprimento do dever de pagamento das cotas pelos sócios, como um dos principais obstáculos que prejudica o funcionamento da associação e impossibilita o desenvolvimento de actividades. Continuam a agir contra as acções do Estado sempre que considerarem que estas não sejam justas para os operadores de mercados, mas não tomam iniciativas no sentido de revindicar as melhores condições de trabalho para os seus membros.

\section{Associação de Retalhistas do Mercado do Bairro Militar (ARMBM)}

0 mercado do Bairro Militar, apesar de se situar no bairro mais populoso da cidade de Bissau, não tem nenhuma infra-estrutura própria que suporte o seu funcionamento. Situado ao longo da rua principal que dá acesso ao bairro, é constituído por várias lojas, cacifos, bancas, e, em grande maioria, postos de venda improvisados, montados directamente no chão. São cerca de mil vendedores, que aí comercializam todos os tipos de produtos e também vários prestadores de serviços que aí desenvolvem as suas actividades.

As condições de trabalho são bastante precárias e, tendo em conta que do trabalho dos comerciantes depende a subsistência das suas famílias e que não é fácil encontrar formas alternativas para garantir os meios para a sobrevivência, tornou-se necessário tomar iniciativas que pudessem melhorar as condições em que operam os retalhistas no Bairro Militar. Com este objectivo foi criada em 2001 a Associação de Retalhistas do Mercado do Bairro Militar, que também se comprometeu em servir como intermediário no caso de problemas com a Câmara.

Entretanto, após da ARMBM se juntar a ARMGB, esta última ficou responsável pelo contacto, em nome da primeira, com a Câmara Municipal e Câmara de Comércio. Entre as limitações que prejudicam o seu funcionamento, os membros da associação sublinham a incapacidade de conseguir obter um crédito. "Foi criado um banco. No início o objectivo da criação do Banco, BRS - Banco Regional da Solidariedade - a ideia era de dar créditos aos grupos organizados, legalizados, mas que pudessem apresentar algum fiador. Uma vez vieram à Swissaid negociar connosco se podíamos ser fiadores. Mas é um risco grande porque o país está numa situação difícil. Quando quem 
recebe, não paga, você é obrigado a pagar. Então nós pedimos autorização na sede e não nos deram esta autorização" (Alfredo Handem, Swissaid, Bissau, 12/11/13). Nem mesmo os microcréditos são acessíveis aos comerciantes que pertencem ao sector informal.

Actualmente a associação praticamente não desenvolve nenhuma actividade, indicando a situação política e, em consequência, económica complexa como a razão que impossibilita o sucesso de qualquer iniciativa:"a situação na Guiné está muito complicada. Se não houver ajuda internacional, isto vai cair tudo. (...) Há muito barulho lá fora, acabam por condenar mais a população e não aqueles que fizeram asneiras. As sanções acabam por prejudicar os mais pobres, não prejudicam 0 Presidente da República ou os chefes de Estado-Maior porque estes estão bem. (...) A situação na Guiné-Bissau mudou muito: antes as pessoas em necessidade pediam arroz nas tabancas, agora eles que enviam arroz para tabancas..." (entrevista com membros da ARMBM, Bissau, 12/11/13). De acordo com os seus membros, até não haver melhorias na situação do país, as actividades das associações não vão trazer resultados positivos.

A associação tem as suas necessidades principais bem definidas, mas sente-se obrigada a esperar por uma altura mais adequada para começar a procurar os caminhos para as conseguir.

\section{Associação Nacional dos Vendedores e Exportadores de Fruta e Pescado da Guiné-Bissau (Afrupeixe)}

Uma das mais antigas associações na área de comércio, a Associação Nacional dos Vendedores e Exportadores de Fruta e Pescado da Guiné-Bissau, foi criada em 1997, entretanto nos primeiros cinco anos funcionou de forma informal, tendo sido registada somente em 2002. Foi mais uma associação que surgiu em resultado de abusos que os trabalhadores sofriam da parte do Estado: "Nós estávamos a funcionar com grande dificuldade, porque há uma situação que acontece em vários mercados: a autoridade camarária vem e faz barbaridade, roubam as coisas, levam tudo... Não é o lugar certo para a pessoa poder cuidar dos seus negócios. Ficávamos assim mal... Entendemos o problema e decidimos legalizar, criar associação, fomos até ao tribunal para assim poder proteger as pessoas" (entrevista com os membros da Afrupeixe, Bissau, 13/11/13). Começaram num grupo de 45 pessoas, que cresceu gradualmente e, neste momento, a associação é constituída por cerca de 6000 associados, dos quais dois terços são mulheres.

Afrupeixe, em comparação com outras associações estudadas ao longo da pesquisa, tem o plano de actividades mais desenvolvido, actuando de forma muito concreta e facilitando o desempenho de trabalho aos seus associados: "Conseguimos produzir documentos, facilitar aos membros de organização a viajar, tanto no país, como nos países vizinhos. Porque há dificuldades. Às vezes o membro de organização faz uma viajem até Guiné Conacri e até Mali, Senegal, mas não tem este documento, este crachá que nós temos aqui. Vai ter problemas. Na fronteira, não consegue passar com estes produtos. Há muitos abusos, cobranças ilegais. Mas com este crachá conseguimos mostrar que a pessoa faz comércio de produtos. Temos que combinar com o Estado (...), comunicar onde a pessoa está. Também conseguimos organizar uma formação para os membros, para dar mais força, mais eficácia, mais 
visão para a organização. Fizemos isso com a Swissaid e com a Câmara de Comércio. (...) Também, anualmente, ajudamos os membros a participar nas feiras, nos países vizinhos" (entrevista com os membros da Afrupeixe, Bissau, 13/11/13). Mas também aqui há vários aspectos que influenciam de forma negativa o funcionamento da associação e estes normalmente tem a ver com a situação política. No caso desta associação, os seus membros foram prejudicados seriamente na sequência do conflito de 1998: antes do conflito, conseguiram um financiamento, mas o início da guerra dificultou o cumprimento dos prazos de pagamento. Conseguiram, mas só com ajuda de familiares.

A partir desta altura nunca mais obtiveram nenhum financiamento ou crédito, mesmo que já várias vezes tenham tentado apresentar as suas candidaturas a várias instituições. Tem a consciência da sua grande incapacidade: de não estarem preparados para elaboração de propostas adequadas e que cumpram todas as exigências dos financiadores. "Precisamos de alguém que pudesse preparar os projectos, procurar financiamentos" (entrevista com os membros da Afrupeixe, Bissau, 13/11/13). E desta forma, gradualmente, realizar os seus planos e responder às necessidades dos associados, como indivíduos e como grupo.

\section{Associação de Retalhistas do Mercado Caracol (ARMC)}

A Associação de Retalhistas do Mercado Caracol foi criada há vinte anos, em 1995, mas até agora não chegou de ser registada e desenvolve as suas actividades de forma informal. Um prolongado período de problemas internos, relacionados com a excessiva autoridade do ex-presidente da associação, ultimamente substituído por uma outra pessoa, não permitiu um progresso continuo em relação às suas acções.

Criada por um grupo de pessoas para lidar com os problemas que sentiam, rapidamente abrangeu todos os vendedores do mercado. 0 número destes aumentava gradualmente, o que tinha a ver com falta de espaço no mercado vizinho, Bandim: "Como no Bandim não havia mais espaço, mandaram a gente para cá e começaram a vender aqui" (entrevista com os membros da ARMC, Bissau, 13/11/13). Actualmente os associados entrevistados estimam o número dos vendedores do Caracol, incluindo os que têm cacifos e os que vendem no chão, em 1000 pessoas.

Este é o mercado mais barato de todos. "Os que estão no Bandim, vêm aqui, compram os produtos e levam para lá, para vender" (entrevista com os membros da ARMC, Bissau, 13/11/13). A0 mesmo tempo, este é o mercado com as piores condições higiénicas e sanitárias. Entretanto, nas afirmações dos novos corpos directivos sente-se uma grande vontade de mudança e uma forte dinâmica no sentido de melhorar a situação em que trabalham diariamente centenas de pessoas e circulam multidões de clientes. "Agora queremos preparar os cartões para identificar as pessoas que estão a vender no mercado. (...) Tem uma bomba de água aí, quer fazer aí. A casa de banho que foi encerrada queremos reabrir também. Como o pavimento do mercado não existe, queremos pavimentar o mercado. Queremos marcar limpezas, cada semana. Mercado está totalmente sujo, quando você sai daqui, você vai ver... Os associados vêem isso e não podem ficar com braços cruzados. Vamos comprar lixivia, vamos comprar luvas e vamos limpar. (...) Queremos fazer um portão 
de ferro e balcão para vender peixe..." (entrevista com os membros da ARMC, Bissau, 13/11/13). A forma de angariação de meios para estas acções ainda não foi definida, mas espera-se que assim que consigam legalizar a organização, esta parte do processo se torne mais fácil. Mas, em primeiro lugar, precisam de pôr fim à guerra com o antigo presidente, recensear os operadores do mercado e confirmar as listas dos membros da associação, verificando se estas se encontram actualizadas.

\section{Transporte \\ Associação dos Transportadores Sector de Cacheu (ASTRASECA)}

Única associação entrevistada fora da cidade de Bissau, a recém-criada Associação dos Transportadores Sector de Cacheu, demostra os planos de actividades bastante mais abrangentes do que os das outras organizações.

A associação pretende organizar todos os trabalhadores ligados ao sector de transportes na zona de Cacheu, organizar a paragem em Cacheu, assim como o sistema de cobrança de pagamentos aos passageiros, e desta forma, por um lado, ajudar aos operadores do sector, permitindo uma prestação de serviço mais organizada e, por outro lado, servir a toda a sociedade de Cacheu, melhorando as condições de vida dos habitantes da localidade. "Nós vivemos a realidade de Cacheu: não há trabalho, não podem ganhar dinheiro. Tem que viver através de mulheres que estão a fazer trabalho. E por isso nós calculamos para organizar e construir um recinto. Abrimos cacífe para as mulheres que não podem deixar os seus filhos de ir estudar lá fora por causa de dificuldade, outras não tem marido, outras tem marido, ou o marido não tá a trabalhar, só mulher que está a trabalhar. E esse dinheiro - ficava dinheiro aqui - para comprar arroz para semear. (...) Se no caso o Estado oferecer este espaço para paragem, este dinheiro nos vamos gastar para comprar semente e preparar a paragem e fazer aqueles cacifos. (...) Todos podem ganhar com esta associação, os que não têm dinheiro, os que não trabalham. (...) A associação vai resolver os problemas dos condutores; dos condutores em relação aos proprietários dos carros; dos ajudantes. Se esse chofer está legalizado, paga a sua quota, quando o chofer está doente, damos um apoio para poder se tratar. Quando já estiver bem, então vai contribuir, depositar dinheiro" (entrevista com os membros da ASTRASECA, Cacheu, 10/11/13). A iniciativa partiu dos próprios interessados: operadores do sector de transportes e habitantes da região de Cacheu.

Actualmente estão a preparar toda a documentação necessária para registar a associação, entretanto já puseram em prática o sistema de cobranças e a organização da paragem de Cacheu. A associação, já nesta fase mesmo inicial, está constituída por cerca de 60 membros, mas a previsão é de multiplicar este número nos próximos meses, já que há dezenas de pessoas interessadas em fazer parte dela. Consideram que só estando organizados, conseguem melhorar as suas condiç̧ões de trabalho e de vida, e só através de uma organização poderão obter alguns financiamentos externos que os ajudarão a alcançar os seus objectivos. 


\section{Outras áreas de actividade}

\section{Ghatenkar Ghaba na Ubon /Ajuda Mútua/}

A Associação de Ajuda Mútua, Ghatenkar Ghaba na Ubon, foi criada em 1992 e registada um ano depois. 0 seu surgimento tinha a ver com a necessidade de arranjar um espaço adequado ao cultivo de legumes por várias mulheres que através desta ocupação conseguiam os meios de subsistência. Já como grupo organizado, colocaram o seu pedido ao Ministério de Agricultura que cedeu um terreno, inicialmente localizado noutro lugar, que, entretanto, foi considerado como pouco adequado às necessidades do grupo, e, por causa disso, o grupo foi transferido para o sítio que ocupa agora, situado nos arredores de Bissau, na Granja de Pessubé. Como a terra só pode ser cultivada por mulheres, a associação é praticamente feminina. Somente três homens fazem parte dela - são os maridos de mulheres proprietárias de terra, que já morreram e deixaram estes pedaços para cultivo aos seus maridos.

A associação começou as suas actividades de forma bastante dinâmica e organizada e ao longo dos anos que seguiram conseguiram alguns apoios externos, tanto da parte do governo, como de algumas ONG's que operam na Guiné-Bissau (entrevista com membros da Ghatenkar Ghaba na Ubon, Bissau, 13/11/13). 0 arrefecimento começou há alguns anos, com o aumento de dificuldades em conseguirem apoios financeiros.

Entretanto, a associação continua a funcionar porque só desta forma, através da organização das cultivadoras, conseguem resolver o problema da rega (compra de combustível para o gerador) e rejeitar as novas exigências por parte do governo, que decidiu, há pouco tempo, introduzir uma taxa que obriga cada mulher a efectuar um pagamento mensal por utilização da terra. As mulheres não consideram que o pagamento desta seja possível, tendo em conta a situação difícil em que a maioria delas se encontra e também a situação da população em geral cujo poder de compra diminuiu bastante nos últimos anos (entrevista com membros da Ghatenkar Ghaba na Ubon, Bissau, 13/11/13).

Através de acções conjuntas, tentam opor-se a esta invenção do governo e ultrapassar outras dificuldades que sentem, não só como trabalhadores informais, mas também como chefes de família e responsáveis pela educação dos filhos. 0 investigador guineense, Alfredo Handem, que dedicou um estudo de caso à associação Ghatenkar Ghaba na Ubon, chega à conclusão após a análise desta organização, que "não restam dúvidas de que as dinâmicas organizacionais que funcionam no contexto da economia informal desempenham um papel importante na luta contra a pobreza e na sobrevivência da família guineense" [Handem 2013: 15].

\section{Associação Nacional de Produtores e Promotores de Arte (ANAPPA)}

A associação, que tem "arte" no seu nome, é frequentemente designada como a associação de artesãos. No entanto, como explica o seu presidente "ANAPPA significa Associação Nacional dos Produtores e Promotores de Arte. Quem produz e quem promove - todos estão acolhidos" (Presidente 
da ANAPPA, Bissau, 15/11/13). Não está clara e definida pelos membros da associação a diferença entre um artesão e um artista, mas o que une estas pessoas é a sua forma de ganhar a vida - através da criação de peças de arte e/ou artesanato.

A associação foi criada em 2004 e inicialmente contava com cerca de 60 membros. Antes a venda de artesanato decorria perto do Mercado Central de Bissau, mas após o incêndio os artesãos ficaram sem espaço adequado para a venda dos produtos. A associação fez um pedido à Câmara e esta cedeu um terreno para a instalação do Mercado de Artesanato. Até agora o espaço não foi remodelado - após um período de obras, logo no início, a Câmara mandou parar a construção dos cacífos e outros arranjos, sem apresentar nenhum motivo para tal, e depois do Golpe de Estado, não conseguiram permissão para a continuação as obras.

Actualmente o número de membros da associação está estimado em cerca de 200 pessoas e abrange os criadores de toda a Guiné-Bissau. Este foi exactamente um dos primeiros objectivos da sua constituição, como explica o presidente: "Na Guiné-Bissau há muitos artesãos. Estes artesãos não se conheciam, não tinham intimidade, não tinham espaço para trabalhar em conjunto. Até agora tem muitos artesãos que estão fora de artesanato. Há muito talento. Este foi o meu sonho - de juntar todo o talento guineense para trabalhar arte, para mostrar ao mundo o que é a GuinéBissau, o que é a arte da Guiné-Bissau. Porque a arte da Guiné-Bissau não é divulgada na televisão, na rádio. Nós procuramos saída para artesanato neste beco sem saída. E este é o nosso sonho para ajudar a todo Guineense. (...) Nós ensinamos muitas pessoas a trabalhar. E assim eles conseguem resolver muitos problemas deles" (Presidente da ANAPPA, Bissau, 15/11/13).

Artesãos e artistas, tanto na Guiné, como noutras partes de mundo (ex. Bialoborska 2013), lidam com os problemas de vários níveis. Além de informalidade, em que desenvolvem a sua actividade, e todas as consequências a esta ligadas, têm que enfrentar o problema de escoamento de produtos - as peças produzidas por eles não são consideradas como produtos de primeira necessidade e por isso a sua comercialização pode ser bastante complicada, especialmente nos países que se encontram em crise e os que não têm grande afluência de turistas. Em Bissau a grande parte das criações é vendida aos turistas, cujo número é bastante reduzido. Perguntando sobre o número dos visitantes que diariamente aparecem no Mercado, o Presidente responde, a rir: "Há dias que vêm 2, 3, 4, 5... Mas não é todos os dias. Podem passar 5-6 dias e ninguém vende nada. Em Bissau não há turistas. A situação da cidade, a questão de segurança, meios de transporte... Tem que se mudar muito. Há turistas na ilha... Mas eles nem sequer vêm aqui. Turista que vem a Bissau é mais turista francês, mas muito pouco. (...) Guiné tem muitas zonas boas, ricas em história. Acho que se 0 Estado tiver a visão para o turismo, 0 Estado poderá fazer muito. (...) Este podia ser um fundo para o Estado da Guiné" (Presidente da ANAPPA, Bissau, 15/11/13). A associação, que neste momento tem como prioridade o registo da organização e 0 recomeço de actividades já de forma legal e como uma associação reconhecida, tem os seus objectivos bem definidos e as primeiras necessidades identificadas. Sentem falta de apoio técnico, da parte das pessoas com formação adequada, que lhes pudessem ajudar na elaboração dos projectos e candidaturas para financiamentos. Afirmam que só como grupo organizado conseguem encontrar solução de vários problemas com que cada um individualmente tem que lidar cada dia. 


\section{Especificidades dos processos de organização dos trabalhadores infor- mais na Guiné-Bissau}

Através de exemplos acima apresentados, aos quais se juntam algumas conclusões da observação directa desenvolvida durante a pesquisa de terreno, podem ser indicadas algumas características específicas dos processos de organização dos trabalhadores informais na Guiné-Bissau. Praticamente todas as organizações percorreram o mesmo caminho: desde as primeiras ideias sobre a sua criação e os motivos que influenciaram este passo, através de mudanças de dinâmica das actividades - diferente na fase inicial e nas fases seguintes - até à estrutura organizacional e planeamento de acções.

0 que distingue estas associações das associações noutros contextos africanos são as circunstâncias que levam a sua constituição. Esta acontece sempre na sequência das necessidades sentidas pelos próprios trabalhadores e após a sua própria análise de situação. Não foram verificadas, como acontece noutros PALOP [ex. Bialoborska 2013, Lopes 2010, Feliciano et al. 2008], nenhumas acções desenvolvidas pelo Estado, organizações não-governamentais e sindicatos dos trabalhadores formais, no sentido de organizarem ou motivarem os trabalhadores informais para criarem organizações no seu meio, juntando as pessoas da mesma categoria profissional que supostamente lidam com o mesmo tipo de problemas. Todas as associações guineenses foram criadas pelos próprios trabalhadores e foram eles que sentiram a necessidade de se organizarem para melhor conseguirem lidar com os problemas que diariamente têm de enfrentar. Nota-se que o motivo principal tinha quase sempre a ver com a resistência contra as acções bastante injustas e injustificadas por parte de Estado e não, por exemplo, com as dificuldades que sentiam como operadores de uma certa área profissional ou como responsáveis pela subsistência das famílias. Isto pode indicar que vários assuntos podem ser resolvidos individualmente ou através de ajuda dos grupos mais pequenos, não-oficiais, mas quanto às questões que envolvem órgãos de Estado, é necessária uma maior visibilidade e força de argumentação e esta só pode ser conseguida se agirem como um grupo unido e organizado. Nem todas as associações chegam a proceder ao acto de registo logo no início da sua actividade. Às vezes isto acontece uns meses depois, noutros casos pode ocorrer só depois de vários anos de funcionamento de forma informal. Normalmente, logo no início - tanto no caso de associações que seguem a sua constituição com o acto de registo no notário, como as que operam sem registo por um período prolongado - são elaborados os estatutos da associação e eleito o seu corpo directivo. Estabelece-se o valor de inscrição, de cotas e outras obrigações dos associados. É elaborado um plano de actividades, tanto de curto, como de longo prazo, e os objectivos das organizações estão devidamente articulados.

0 número de membros de associações tem a tendência de aumentar gradualmente, especialmente nos primeiros meses de funcionamento destas. Surgem como os grupos relativamente pequenos, mas que, com o passar do tempo, incluem cada vez mais pessoas, chegando, em vários casos, de abranger a maioria dos operadores ligados com o espaço onde desenvolvem as suas actividades. Na fase inicial os grupos controlam as inscrições de novos membros, emitindo cartões de 
associados, cobrando taxa de inscrição e cotas mensais. No entanto, as associações que já existem há vários anos não actualizam as listas de associados e muitas vezes não têm a certeza quanto ao número de membros que fazem parte delas. Também as cotas deixam de ser pagas pelos sócios, na maioria dos casos por falta de condições financeiras.

Notam-se variações significativas em relação à dinâmica das actividades desenvolvidas. Em todos os casos, o primeiro período - que segue o acto de constituição, mas não tem uma média de duração definida - é a fase mais dinâmica e repleta de numerosas acções desenvolvidas. Com tempo e com 0 aumento do número de obstáculos encontrados, e também por causa de vários insucessos com os quais têm que lidar, a dinâmica inicial começa a ser gradualmente reduzida, os planos diminuídos até ao mínimo e, em vários casos, as associações perdem a força que tiveram deixando de agir e incentivar actividades que pudessem melhorar a vida dos seus membros. A falta de insistência tem também a ver com o facto de se tratar de grupos de pessoas que não possuem a formação adequada para elaboração de programas que pudessem permitir de consegui-los ou, pelo menos, tentar obter alguns financiamentos externos. Nos exemplos apresentados, todas as associações que estavam numa fase inicial da sua existência (ex. ASTRASECA, ANAPPA, renovada ARMC) tinham os planos bastante desenvolvidos, o resto - as que já contam com uma história prolongada do seu funcionamento (ex. ASCOMC, ARMBM, ARMGB) - permanecia numa espécie de letargo, agindo somente em alguns casos que exigiam a intervenção do grupo, especialmente todos os assuntos que envolviam negociações com o Estado.

\section{Constrangimentos no funcionamento das organizações dos trabalhado- res informais na Guiné-Bissau}

Os operadores do sector informal na Guiné-Bissau, ligados a várias áreas de actividades económicas, constataram a importância de criação de organizações. Através destas pretendem ganhar mais voz, visibilidade e reconhecimento ${ }^{16}$. No entanto as organizações guineenses, mesmo as mais dinâmicas, ao longo da sua existência tornam-se cada vez menos eficazes, encontrando uma série de constrangimentos que dificultam o seu funcionamento e diminuem a quantidade das actividades desenvolvidas. Os constrangimentos podem ser divididos em duas categorias: internos, ligados à própria estrutura e organização da associação, e externos, que englobam várias condicionantes que não podem ser alterados ou melhorados pelos próprios membros das associações.

Entre os principais constrangimentos internos, destacam-se:

1) Baixo nível de formação dos membros.

Dificulta o progresso no desempenho das actividades programadas, impede a realização de um

16. "Os três V, "voice, visibility, and validity", definidos como os principais objectivos de organizações dos trabalhadores informais, pela WIEGO (Women in Informal Employment: Globalizing and Organizing). Ver em: http://wiego.org/. 
diagnóstico adequado em relação às possíveis parcerias que possam ser constituídas para aumentar a eficácia das acções, impossibilita a preparação de candidaturas para financiamentos ou projectos que estejam aptos a ser apresentados às diversas instituiç̧ões no sentido de angariar apoios.

\section{2) Falta de experiência associativa.}

Prejudica o funcionamento das associações que não conseguem, a longo prazo, agir como grupo. Nem sempre o debate e a consulta com vários membros antecedem as actividades desenvolvidas, o que causa insatisfação de uma parte dos associados.

3) Conflitos internos. Jogo de interesses.

Em alguns casos nota-se um jogo de interesses por parte das pessoas que normalmente ocupam cargos directivos, amplamente criticado por membros de associações. Há presidentes autoritários, há presidentes que se aproveitam do cargo que ocupam - ou, pelo menos - assim são vistos pelos membros de associações.

\section{4) Incapacidade organizacional}

Foi constatada a falta de capacidade de organizar, de forma sistemática e regular, a documentação e os registos dos associados. 0 número de sócios raramente é conhecido, as listas não costumam ser actualizadas. As quotas raramente são pagas por períodos maiores do que os primeiros meses e mesmo isto às vezes não acontece.

5) Falta de apoio técnico.

Este constrangimento, que pode também ser considerado como de natureza externa, tem a ver com 0 modo de constituição das associações. Normalmente são criadas pelos próprios trabalhadores, para resolver um definido problema, e não incorporam as pessoas não ligadas aos grupos profissionais no âmbito dos quais operam. Esta ausência das pessoas com capacidade de fornecer algum apoio técnico leva à incapacidade de encontrar melhores e mais eficazes soluções para os problemas com os quais lidam e que pretendem superar.

\section{Constrangimentos externos:}

1) Instabilidade política

A instabilidade política é considerada como a principal causa de mau funcionamento de qualquer tipo de associações e de insucesso de diversas iniciativas. Esta tem várias consequências, entre as quais duas podem ser indicadas como as mais prejudiciais para as organizações dos trabalhadores informais. Os acontecimentos políticos no país trazem as respostas pouco positivas por parte da comunidade internacional. Assim aconteceu em 2012, após o último golpe de estado, quando vários apoios financeiros foram anulados. Outro aspecto negativo é a falta de continuidade das acções, tanto por parte de governo, como outras entidades. No ano 2013, ano de transição, todas as associações entrevistadas indicaram este constrangimento como 0 que mais influenciou a situação actual em que a organização se encontrava e que não conseguia 
ser resolvida. A única hipótese indicada por membros de associações foi a de ficar à espera de mudança.

\section{2) Falta de apoios financeiros.}

As limitações quanto os impactos de actividades desenvolvidas, assim como a eficácia destas, estão directamente relacionadas com a impossibilidade de conseguir obter apoios financeiros. Sem financiamentos externos muitas das necessidades das associações não podem ser satisfeitas e muitos dos planos ficam sem efeito. Este factor, até certo ponto, tem a ver com a falta de capacidade de elaborar projectos de forma adequada ao nível das exigências dos potenciais financiadores, especialmente a nível internacional. A falta de experiência associativa e inexistência da tendência para criarem redes ou plataformas também tem alguma influência em relação à incapacidade de conseguirem os fundos. No entanto, mesmo que consigam ultrapassar estas dificuldades, não têm nenhuma garantia de arranjar apoios. Em várias situações, as promessas de instituições financiadoras não foram cumpridas, o que faz com que muitas associações não repitam as tentativas de procura.

\section{3) Impossibilidade de obter créditos e difícil acesso ao microcrédito.}

Os trabalhadores informais não reúnem as condições necessárias para conseguirem obter os créditos num dos bancos que operam na Guiné-Bissau. Também as associações não cumprem todas as exigências dos bancos. 0 sistema de microcrédito podia constituir uma alternativa nesta situação, entretanto o seu funcionamento ainda se encontra em fase embrionária. Em 2013 somente cinco instituições de microfinanças estavam a operar com eficácia na Guiné-Bissau, não conseguindo responder a todas as solicitações [Arvanitis 2014].

\section{Conclusões}

Na Guiné-Bissau os processos de organização entre os trabalhadores informais são bastante desenvolvidos, abrangem praticamente todas as áreas de actividades económicas e atingem a grande parte dos trabalhadores informais. Todas as iniciativas organizacionais emergem dentro do próprio meio dos trabalhadores e são desenvolvidas no sentido bottom-up, não sendo incentivadas por instituições estatais, sindicatos de trabalhadores formais ou organizações não-governamentais. Isto indica a maturidade da sociedade civil guineense, que através de processos de organização pretende mudar as condições de vida das pessoas. Mais do que as consequências directas de informalidade, o descontentamento com acções do Estado é considerado como o principal impulso para se organizarem e desta forma conseguirem, com mais força, responder aos abusos que, com frequência, têm que enfrentar. A melhoria das condições de trabalho vem como a prioridade logo a seguir, assim como a tentativa de melhor organizar os lugares onde desenvolvem actividade, permitindo desta forma o seu bom funcionamento, tanto do ponto de vista dos trabalhadores envolvidos, como dos clientes. 
Mesmo as mais dinâmicas das associaç̃̃es, que iniciam o seu funcionamento com os planos bem definidos, encontram, ao longo do caminho, vários constrangimentos que influenciam de forma negativa 0 desempenho das suas actividades. Há factores internos e externos que prejudicam o funcionamento das associações e fazem com que estas abrandem de forma significativa o ritmo e desistam da implantação dos planos programados e também da projecção de novas actividades. Falta de formação, de experiência, de apoio técnico, por um lado e as consequências de instabilidade política, impossibilidade de obter créditos e financiamentos, por outro lado, limitam a eficácia das organizações. Entretanto, todas elas, mesmo as que actualmente se encontram num período mais passivo da sua actividade, têm a consciência das principais necessidades dos associados e se conseguirem algum tipo de encaminhamento, algumas indicações por parte das pessoas ou organizações com maior experiência (ex. associações como RAJ - Rede de Associações Juvenis ou a ONG Força Guiné) podem melhorar bastante o seu desempenho, voltar à dinâmica inicial ou até aumentá-la e, desta forma, mudar gradualmente a situação precária em que milhares dos trabaIhadores informais guineenses se encontram.

\section{Referências bibliográficas}

AGUILAR, Renato, Huco MONTEIRO e Aquino DUARTE (coord.)

2001: Bandim. Subsídios para uma política de apoio ao pequeno negócio, Bissau: Instituto Nacional de Estudos e Pesquisa ARVANITIS, Yannis

2014: Providing Efficient Banking Services in a Fragile Environment. Structure, Performance and Perspectives of the Banking Sector in Guinea-Bissau, African Development Bank, West Africa Regional Department, Note 01, July 2014 BIALOBORSKA, Magdalena

2013: Processos de organização na economia informal em Cabo Verde: estudo de caso sobre a Associação de Artesãos de Mindelo CAMIN, Dissertação de Mestrado em Estudos Africanos, Lisboa: ISCTE-IUL

CAMARÁ, Samba Tenem

2010: Lumo - Estatuto, funcionamento e organização dos Mercados Periódicos na Guiné-Bissau - estudo de caso no lumo de Mafanco, Dissertação de Mestrado em Estudos Africanos, Lisboa: ISCTE-IUL

DIAS, Eduardo Costa

2013: "From the Unbearable "Resilience" of Coupism to Ethnicisation: a Short Journey for the Armed Forces of Guinea-

Bissau", Nordic Journal of African Studies 22(1\&2), pp. 6-22

DUARTE, Aquino e Aristides Gomes

1996: "O Sector Informal", in: O Programa de Ajustamento Estrutural na Guiné-Bissau. Análise dos efeitos Sócio-Econó-

micos, Bissau: Instituto Nacional de Estudos e Pesquisa, pp. 97-115

FELICIANO, José Fialho, Carlos Manuel LOPES e Cristina Udelsmann RODRIGUES

2008: Protecção Social, Economia Informal e Exclusão Social nos PALOP, São João do Estoril: Principia

GOMES, Patrícia

2008: "As mulheres do sector informal. Experiências da Guiné-Bissau", comunicação apresentada no VI Congresso de Estudos Africanos no Mundo Ibérico África, puentes, conexiones e intercambios, Universidade de Gran Canaria, 7-9 Maio 2008, Gran Canaria

HANDEM, Alfredo

2013: "As dinâmicas organizacionais no contexto informal. 0 caso da Associação de Mulheres Ghatenkar Ghaba na Ubom (Ajuda Mútua)", policopiado 
HART, Keith

1970: "Small-scale Entrepreneurs in Ghana and Development Planning", Journal of Modern African Studies, 6, pp. 104-120

HART, Keith

1973: "Informal Income Opportunities and Urban Employment in Ghana", Journal of Modern African Studies, 11(01), pp. 61-89

INSTITUTO NACIONAL DE ESTATÍSTICA

2011: Inquérito Ligeiro para Avaliação da Pobreza (ILAP2), Bissau: INE

LINDELL, Ilda (ed.)

2010: Africa's Informal Workers. Collective agency, transnational organizing and urban Africa, Uppsala: The Nordic Africa Institute, London: Zed Books

LOPES, Carlos M.

2010: "Dinâmicas do associativismo na economia informal: os transportes de passageiros em Angola", Análise Social, vol. XLV (195), pp. 367-391

LOURENÇO-LINDELL, IIda

2002: Walking the Tight Rope. Informal Livelihoods and Social Networks in a West African City, Stockholm: Department of Human Geography, Stockholm University

MENDES, Pedro Rosa

2013: "Respostas de paz à impunidade e exclusão", relatório apresentado na mesa-redonda da Civil Society Dialogue Network (CSDN) Guinea-Bissau: Peacebuilding responses to impunity and exclusiveness, 6- 7 Jun 2013, Bruxelas

MINISTÉRIO DA ECONOMIA, DO PLANO E INTEGRAÇÃO REGIONAL

2011: Segundo Documento de Estratégia Nacional de Redução da Pobreza da Guiné-Bissau (DENARP II), Bissau

MONTEIRO, António Issac (coord.)

1996: O Programa de Ajustamento Estrutural na Guiné-Bissau. Análise dos efeitos Sócio-Económicos, Bissau: Instituto Nacional de Estudos e Pesquisa

OIT

1972: Employment, incomes and equality. A strategy for increasing productive employment in Kenya, Geneve: International Labour Office

1991: The Dilemma of the Informal Sector, report of the Director General, 78th International Labour Conference, Geneve: International Labour Office

1999a: Report of Director General Decent Work, 87th International Labour Conference, Geneva

1999b: "Conclusions and recommendations", International Symposium on Trade Unions and the Informal Sector, Geneva, 18-22 October 1999.

2002: Decent work and the informal economy, Report VI, 90th International Labour Conference, Geneva: International Labour Office

2007a: For debate and guidance. The informal economy, relatório de Governing Body Committee on Economic and Social Policy, GB.298/ESP/4, Geneva: International Labour Ofice

2007b: The informal economy: enabling transition to formalization, Tripartite Interregional Symposium on the Informal Economy, Geneva: International Labour Office

2009: The informal economy in Africa. Promoting transition to formality: Challenges and strategies, Geneva: International Labour Office, Employment Sector and Social Protection Sector

ROGEL, Guillermo (coord.)

2006: Forces for Change. Informal economy organizations in Africa, London: War or Want, The Workers Education Association of Zambia, The Alliance for Zambia Informal Economy Associations.

SANTOS, Gustavo Plácio dos

2014: "Elections in Guinea-Bissau: A Roadmap for Restoration of Constitutional Order", IPRIS Viewpoints, № 139, Lisboa, Portuguese Institute of International Relations and Security (IPRIS)

UNDP

2014: Human Development Report 2014. Sustaining Human Progress: Reducing Vulnerabilities and Building Resilience, New York: United Nations Development Programme. 


\section{Imprensa}

DW, 19/04/2012, "Militares e oposição anunciam acordo sobre "transição democrática" na Guiné-Bissau", António Rocha, disponivel em: http://www.dw.de/militares-e-oposi\%C3\%A7\%C3\%A30-anunciam-acordo-sobretransi\%C3\%A7\%C3\%A30-democr\%C3\%A1tica-na-guin\%C3\%A9-bissau/a-15897726.

DW, 17/04/2012, "União Africana suspende Guiné-Bissau por prazo indeterminado", António Rocha, disponível em: http:// www.dw.de/uni\%C3\%A30-africana-suspende-guin\%C3\%A9-bissau-por-prazo-indeterminado/a-15889037.

DW, 13/04/2012, "Comunidade internacional condena os recentes acontecimentos político-militares na Guiné-Bissau", António Rocha, disponível em: http://www.dw.de/comunidade-internacional-condena-os-recentes-acontecimentos-pol\%C3\%ADtico-militares-na-guin\%C3\%A9-bissau/a-15881938.

\section{Artigo pedido à autora}

Recebido a: 27/Novembro/2014

Aceite para publicação: 7/Dezembro/2014

\section{Title}

Dynamics and constraints in the organizing processes of informal workers in Guinea-Bissau

\section{Abstract}

The processes of organization among informal workers in Guinea-Bissau are usually guided by the dynamics multiplied by various organizations, such as associations, trade unions, and cooperatives. The organizations, both formalized and informal, exist in various sectors of economic activity and involve a significant number of workers.

The lack of accurate data on the size of the informal economy in Guinea-Bissau, does not let us estimate the proportion between the organized informal workers and those who do not belong to the associations. The article presents an analysis of the functioning of some of the organizations - discussing the results of the field research, which included, apart from the interviews with the members and governing bodies, direct observation and informal conversations as well - and it identifies the main constraints that limit the activities planned by the associations, and, therefore, the benefits they can provide to their members.

\section{Key-words}

Informal economy, organizations in informal economy, informal trade, informal transport. 
Investigação e Estudos de Sociologia do Instituto Universitário de Lisboa, pólo CIES_UBI. Licenciada e Mestre em Sociologia pelo ISCTE, concluiu o doutoramento na UBI em 2008 com orientação científica da Professora Karin Wall do Instituto de Ciências Sociais de Lisboa. Os seus principais interesses de investigação incidem na área da Família, Sexualidade, Género e Metodologias Qualitativas. Bibliografia: Santos, F. [2013]. Without ceremony and without papers. The diversity of conjugal cohabitation in Portugal. Journal of Education, Psychology and Social Sciences, vol. 1[1], pp. 31-45. Santos, F. [2012], 0 Papel da Sexualidade nos Percursos de Formaçãa dos Casais Coabitantes: Género, Mudanças Geracionais e Contextos Sociais in Atas do VII Congresso Português de Sociologia, Lisboa: APS. Santos, F. [2010] "0 Abuso Sexual da Criança em Contexto Intrafamiliar" in H. Pereira; M. L. Branco; F. Simões; G. Esgalhado; R. M. Afonso, [Coord.], Educação para a Saúde: Cidadania e Desenvolvimento Sustentado, pp. 900-907, Ed. Covilhã: UBI, ISBN: 978-989-96996-0-1.

[e-mail: namesantos@sapo.pt]

\section{JÚLIO CÉSARTORRES}

Engenheiro. Doutor em Engenharia Eléctrica, Docente na Universidade Federal do Rio de Janeiro (UFRJ), no programa de Mestrado em Engenharia Urbana da Escola Politécnica.

[e-mail: julio@poli.ufrj.br]

\section{LUÍS MASCARENHAS GALVÃO}

Mestre em Lusofonia e Relações Internacionais pela Universidade Lusófona de Lisboa. Ex-Adido Cultural de Portugal em Luanda, Luxemburgo e Bruxelas. Cooperante-formador na Direção Geral de Educação de Adultos em Cabo Verde, membro fundador da AICL (Associação Internacional Colóquios da Lusofonia). Áreas de interesse: interculturalidade, estudos africanos, pós-colonialismos, literaturas africanas, relações internacionais, tradução cultural.

Escritor, ensásta, investigador. Autor de:

Manuel Rui: Percursos Transculturais na obra do escritor. Luanda: UEA (2012); Um Adido Cultural no Luxemburgo - Episódios de uma diplomacia de prosápia. Lisboa: Guerra e Paz (2011); Coisas e Sabores de Língua Portuguesa - on line, nos sites da CPLP e do ACIDI (2010). Estórias de Angola. Lisboa: Editora Prefácio (2007). E outras obras anteriores. Vários artigos recentes em revistas científicas.

[e-mail: Igaivao@sapo.pt]

\section{MAGDALENA BIALOBORSKA}

Antropóloga e musicóloga. Mestre em Estudos Africanos (ISCTE-IUL) e licenciada em Etnologia e Antropologia da Cultura (Universidade de Varsóvia), concluiu o Conservatório Nacional de Música. Produtora cultural, especialiazada nas áreas de música e dança. Foi investigadora no Centro de Estudos Africanos, participou no projecto "Organizações e Representação na Economia Informal nos PALOP: experiências e perspectivas" (REF: PTDC/AFR/113992/2009); desenvolveu trabalho de terreno em Cabo Verde, São Tomé e Príncipe e na Guiné-Bissau. Além dos processos de organização dos trabalhadores informais nestes países, fez pesquisa 
sobre 0 transporte informal e sobre artistas e artesãos enquanto trabalhadores informais. Actualmente desenvolve trabalho sobre a música de São Tomé e Príncipe.

[e-mail: magdabi@gmail.com]

\section{ODÍLIO FERNANDES}

Sociólogo, Mestre em Sociologia Rural pela Universidade de Missouri - Columbia. É Assistente de Investigação no Centro de Investigação e Estudos de Sociologia (CIES) da Faculdade de Ciências Sociais da Universidade Agostinho Neto, tendo como áreas de investigação a Sociologia Rural, a Sociologia da Religião, a Sociologia Histórica, a Sociologia dos Conflitos e a Sociologia do Quotidiano. É referee da revista Ciência e Tecnologia (Luanda, Angola).

[email: odiliotfernandes@hotmail.com]

\section{SÓNIA FRIAS}

Antropóloga. Prof. Auxiliar no ISCSP - Universidade de Lisboa. Investigadora Integrada do CESA/ISEGUniversidade de Lisboa, e colaboradora do CIEG/ISCSP, do CEI/ISCTE-IULe do CEMRI-Uab.

Conduz trabalhos de investigação no campo do Género e Desenvolvimento; Urbanização e Desenvolvimento, Migrações e Relações Interculturais. Tem realizado pesquisa em Angola, Brasil, Cabo Verde e Moçambique. Actualmente coordena um projeto sobre a inserção de migrantes islâmicos em Portugal. Tem publicados, livros e artigos sobre as diferentes temáticas em que tem investigado.

[e-mail: sonia.frias@iscsp.ulisboa.pt]

\section{Livros publicados:}

2014, Casanova, Catarina \& Sónia Frias (coords.). Número Especial Dedicado à Antropologia do Ambiente, col. MEMÓRIAS (16), Lisboa, Sociedade de Geografia de Lisboa.

2013, Frias, Sónia (org.) Leituras de Angola, col. Memória (14), Lisboa, Sociedade de Geografia de Lisboa.

2012, Évora, Iolanda \& Sónia Frias, (coords.), In Progress, Seminário sobre Ciências Sociais e Desenvolvimento em África, CESA - ISEG, Universidade Técnica de Lisboa. Pode consultar-se em: http://pascal.iseg.utl. pt/ cesa/index.php/pt/menupublicacoes/e-book/195

2008, Frias, Sónia (org.), Etnografia e Emocõos, Lisboa, Instituto Superior de Ciências Sociais e Políticas Universidade Técnica de Lisboa.

2006, Frias, Sónia, "Mulheres na Esteira, Homens na Cadeira" Por quanto tempo? Mulheres, economia informal e mudança Cultural: estudo realizado na cidade de Maputo, Lisboa, Instituto Superior de Ciências Sociais e Políticas - Universidade Técnica de Lisboa.

2005, Barata, Óscar Soares e Piepoli, Sónia Infante Girão Frias (coords.), África, Género, Educação e Poder, Lisboa, Instituto Superior de Ciências Sociais e Políticas - Universidade Técnica de Lisboa.

2001, Barata, Óscar Soares e Piepoli, Sónia Infante Girão Frias (coords.), Populações, Ambiente e Desenvolvimento em África, Lisboa, Instituto Superior de Ciências Sociais e Políticas - Universidade Técnica de Lisboa. 